\title{
AVALIAÇÃO DA VARIAÇÃO DA TEMPERATURA CUTÂNEA, PROTEÍNA C REATIVA E VELOCIDADE DE HEMOSSEDIMENTAÇÃO NA ARTROPLASTIA TOTAL DO JOELHO PRIMÁRIA, ISENTA DE COMPLICAÇÕES
}

\begin{abstract}
EVALUATION OF SKIN TEMPERATURE, REACTIVE C PROTEIN, AND HEMOSEDIMENTATION SPEED VARIATION IN UNCOMPLICATED PRIMARY KNEE TOTAL ARTHROPLASTY
\end{abstract}

\author{
lúcio Honório de Carvalho Júnior ${ }^{1}$, Rogério luciano dos Santos², Celso Júnio Aguiar Mendonça², \\ Cícero Teixeira Campos², Marco Antônio Percope de Andrade ${ }^{3}$
}

\section{RESUMO}

Objetivo: Estudar a variação dos valores da temperatura cutânea $(\triangle T)$ do sítio operatório, da proteína $C$ reativa $(P C R)$ e da velocidade de hemossedimentação (VHS) em pacientes submetidos a artroplastia total do joelho (ATJ) primária, tentando estabelecer correlação entre suas curvas ao longo do tempo. Material e Métodos: Esse estudo clínico prospectivo, avaliou 29 pacientes acompanhados por 12 semanas, sendo aferida a temperatura cutânea em ambos os joelhos e realizada dosagem sérica da PCR e VHS. Resultados: Após a comparação entre as variáveis testadas ( $\triangle \mathrm{T}, \mathrm{PCR}$ e VHS), observou-se tanto para o teste de Pearson (avaliação paramétrica), quanto para o de Spearman (avaliação não-paramétrica) que não houve correlação estatística entre elas. A variação da temperatura cutânea segue um padrão diferente do observado tanto para a PCR quanto para a VHS, não existindo correlação entre as curvas. Foi estabelecida a curva padrão das três variáveis, verificando-se redução estatisticamente significativa nos valores da PCR e da VHS entre o pré e o pós-operatório. Conclusão: Não foi observada correlação entre a temperatura cutânea e os níveis de VHS e PCR em pacientes submetidos a ATJ primária, isenta de complicações.

Descritores: Artroplastia; Joelho; Temperatura; Proteína C reativa.

\section{INTRODUÇÃO}

A artroplastia total (ATJ) é o tratamento definitivo para o alívio da dor causada por osteoartrose do joelho, restaurando seu alinhamento e sua função ${ }^{(1,2,3,4)}$.

Infecção pós ATJ é complicação grave que coloca em risco a articulação e ocasionalmente ameaça a vida do paciente $e^{(3,4,5)}$. A incidência de infecção profunda varia entre 1 e $5 \%^{(2,4)}$. Infecção superficial ocorre entre 10 e $20 \%$ dos $\operatorname{casos}^{(2,4)}$.

\section{SUMMARY}

Objective: To study the variation of skin temperature values $(\triangle T)$ on operative site, of reactive $C$ protein $(R C P)$ and of hemosedimentation speed (HSS) in patients submitted to primary knee total arthroplasty (KTA), in an attempt to establish a correlation among its curves over time. Materials and Methods: This prospective clinical study evaluated 29 patients followed up during 12 weeks, with measurements of skin temperature in both knees and RCP and HSS serum dosages. Results: After comparing the variables tested ( $\triangle T, R C P$ and $H S S$ ), no statistical correlation was observed for both the Pearson's test (parametric test) and the Spearman's test (non-parametric test) among variables. Skin temperature variation follows a different pattern from that observed both for RCP and for HSS, with no correlation among curves. A standard curve was established for the three variables, and a statistically significant reduction was seen in RCP and HSS values from pre- to post-operative period. Conclusion: No correlation was observed between skin temperature and HSS and RCP levels in patients submitted to uncomplicated primary KTA.

Keywords: Replacement; Knee; Temperature; C-reactive protein.

Maior freqüência é encontrada em pacientes previamente submetidos a outras cirurgias, portadores de artrite reumatóide (especialmente homens soropositivos) e em pacientes portadores de úlcera de pele ${ }^{(3,4)}$.

Fatores associados à infecção são obesidade, infecção do trato urinário, uso de esteróides, insuficiência renal, diabetes mellitus, desnutrição e psoríase ${ }^{(1,2,3,5)}$. São fatores predisponentes de infecção superficial a anemia, a hipovolemia e o tabagismo ${ }^{(2)}$

Trabalho realizado no Hospital das Clínicas (HC) da Universidade Federal de Minas Gerais (UFMG).

Endereço para correspondência: Rua Olavo Carsalade Vilela 264, Residencial Ipê da Serra, Nova Lima - MG CEP: 34000-000. E-mail: luciohcj@medicina.ufmg.br

1 - Doutor em Ortopedia pela UNIFESP. Professor Adjunto do Departamento do Aparelho locomotor da Faculdade de Medicina da UFMG.

2 - Médico residente em Ortopedia e Traumatologia do Departamento do Aparelho Locomotor da Faculdade de Medicina da UFMG.

3 - Doutor em Ortopedia pela UNIFESP. Professor Adjunto do Departamento do Aparelho locomotor da Faculdade de Medicina da UFMG. Chefe do Serviço de Ortopedia do HC da UFMG.

Trabalho recebido em: 23/09/05 aprovado em 31/01/06 
A proteína $\mathrm{C}$ reativa ( $\mathrm{PCR}$ ) é sintetizada pelos hepatócitos, na fase inflamatória aguda, em resposta a infecção. Seu significado no diagnóstico de infecção aguda e destruição tissular está bem estabelecido(6-10). Seus níveis se alteram de acordo com a atividade da doença, aumentando a partir de 6 horas de infecção e atingindo pico de elevação dois dias após seu início. Retorna ao normal uma semana depois de começado o tratamento adequado ${ }^{(1,6-10)}$. Métodos modernos, quantitativos e rápidos, têm aumentado significativamente o potencial de uso dos níveis séricos de $\mathrm{PCR}^{(1,6,7)}$.

A velocidade de hemossedimentação (VHS) é importante teste laboratorial no diagnóstico de infecções pós-operatórias. Seus valores elevam-se a partir de 48 horas do início do quadro infeccioso, ocorrendo pico de elevação entre três e cinco dias, retornando ao valor normal aproximadamente três semanas depois de iniciado o tratamento adequado ${ }^{(1,5,6,7,10)}$. Seu valor, assim como o da PCR, é limitado pela influência de outras doenças ou complicações pós-operatórias, sendo difícil estipular limites absolutos para seus níveis séricos apropriados ${ }^{(5)}$.

A temperatura cutânea do sítio cirúrgico é um sinal inespecífico para avaliação de infecção no pós-operatório imediato, pois o próprio mecanismo de cicatrização leva a aumento da vascularização pela resposta inflamatória local, aumentando a temperatura ${ }^{(3)}$.

O objetivo desse trabalho é estudar a variação da temperatura cutânea do sítio operatório, dos valores da PCR e VHS em pacientes submetidos a ATJ primária na ausência de complicações clínicas pré e pós-operatórias, na tentativa de estabelecer seus padrões normais e averiguar a existência de uma possível correlação entre eles.

\section{MATERIAL E MÉTODOS}

No período entre Julho de 2004 e Maio de 2005, foram avaliados prospectivamente 29 pacientes submetidos a ATJ unilateral primária portadores de osteoartrose essencial, isentos de quaisquer complicações pré e pós-operatórias.

Todos os pacientes foram operados por dois dos autores (LHCJ e MAPA) no HC da UFMG.

Foram excluídos da amostra três pacientes que apresentaram infecção superficial, um com trombose venosa profunda, um com infecção do trato urinário e quatro que não retornaram de forma regular para as avaliações. Todos os demais 20 pacientes foram acompanhados por 12 semanas a partir do pré-operatório imediato. Treze pacientes eram do sexo feminino e sete do masculino, com idades variando entre 58 e 75 anos, com média de 65,85 anos.

A temperatura cutânea de ambos os joelhos foi aferida no pré-operatório imediato, 48 horas, uma, duas, quatro, oito e doze semanas de pós-operatório usando-se termômetro de contato modelo Digital Thermo ${ }^{\circledR}$ da marca Alla France ${ }^{\circledR}$ apoiado na face ântero-medial dos joelhos por um período de três minutos. Para análise foram registradas as diferenças da temperatura entre os dois lados $(\Delta T)$. No mesmo ato, foram coletadas amostras de sangue para realização da dosagem sérica da PCR e da VHS, todas realizadas pelo mesmo laboratório. O método utilizado na medição da PCR foi a Nefelometria, utilizando aparelho Beckman Array 360 System, cujo valor de referência foi padronizado em menor que oito miligramas por litro para o resultado ser considerado negativo. A VHS foi dosada através da metodologia de Westergreen modificado, com material da Seditainer ${ }^{\circledR}$ - Becton Dickinson ${ }^{\circledR}$, cujos valores de referência estão padronizados de acordo com a tabela a seguir (tabela 1):

O projeto de pesquisa foi aprovado pelo Comitê de ética em pesquisa da instituição. Foi obtido termo de consentimento pós-informado por escrito de todos os participantes.

Para a análise estatítica dos dados foi utilizado o coeficiente de correlação paramétrica de Pearson (r).

As comparações de correlação estatística foram testadas par a par, para duas das três variáveis em um determinado intervalo de tempo (por exemplo: comparação entre $\Delta T$ e PCR na primeira semana de pósoperatório).

Para todas as comparações também foi realizada a avaliação não paramétrica (coeficiente de correlação de Spearman).

\section{RESULTADOS}

Obtiveram-se os seguintes resultados para o teste paramétrico de Pearson (Tabela 2):

Após a comparação entre as variáveis testadas $(\triangle T$, PCR e VHS), observou-se tanto para o teste de Pearson, quanto para o de Spearman que não houve correlação estatística ( $r$ próximo de 0 ), mostrando que a variação da temperatura cutânea segue padrão diferente do observado tanto para a PCR quanto para a VHS.

Os Gráficos 1, 2 e 3 demonstram, respectivamente, as curvas individuais do $\Delta \mathrm{T}$, da PCR e da VHS ao longo do tempo (90 dias).

No Gráfico 4 foi realizada a sobreposição das curvas de $\Delta \mathrm{T}, \mathrm{PCR}$ e VHS ao longo do período de acompanhamento (90 dias) sendo possível visibilizar o resultado dos testes estatísticos previamente citados.

Observa-se que todas as variáveis testadas apresentam no primeiro intervalo de aferição (pré-operatório - 48 horas) um aumento dos seus valores da ordem de 3,7 a 4,2 vezes. As curvas de PCR e VHS iniciam redução de seus valores após as primeiras 48 horas de pós-operatório. A PCR decresce de forma mais rápida alcançando níveis inferiores aos do pré-operatório cerca de 28 dias após a cirurgia (4 semanas). 
Por sua vez a VHS somente retorna a níveis inferiores aos pré-operatórios após 56 dias (8 semanas).

A $\triangle T$ apresenta um pico de elevação no primeiro intervalo de aferição (préoperatório - 48 horas), mas mantem-se em ascenção até os primeiros 14 dias de pós-operatório ( $2^{\mathrm{a}}$ semana) e somente após este período inicia sua redução com velocidade inferior à diminuição das outras variáveis. Mesmo após o período de avaliação estipulado nesse trabalho (12 semanas), a $\Delta T$ ainda mantinha-se em declínio, mas acima dos valores aferidos no pré-operatório.

Com o objetivo de avaliar correlação estatística entre os valores pré-operatórios e os valores aos 90 dias de cada uma das variáveis individualmente, obtiveram-se os seguintes resultados para o teste paramétrico de Pearson (Tabela 3):

Com estes resultados observamos que tanto para a PCR quanto para a VHS, há uma diferença estatísticamente significante entre os valores pré-operatórios e os pós-operatórios. Tal fato não pode ser observado para a $\Delta T$, apresentando inclusive correlação negativa.

\section{DISCUSSÃO}

A avaliação clínica pós-operatória pode diagnosticar precocemente uma possível infecção do sítio cirúrgico. A PCR e VHS são exames muito utilizados com essa finalidade, porém apresentam a desvantagem de serem inespecíficos ${ }^{(5-10)}$, podendo estar alterados em diversas doenças que apresentam resposta inflamatória(1). Outros fatores também podem alterar os valores da VHS e da PCR como obesidade ${ }^{(11)}$,

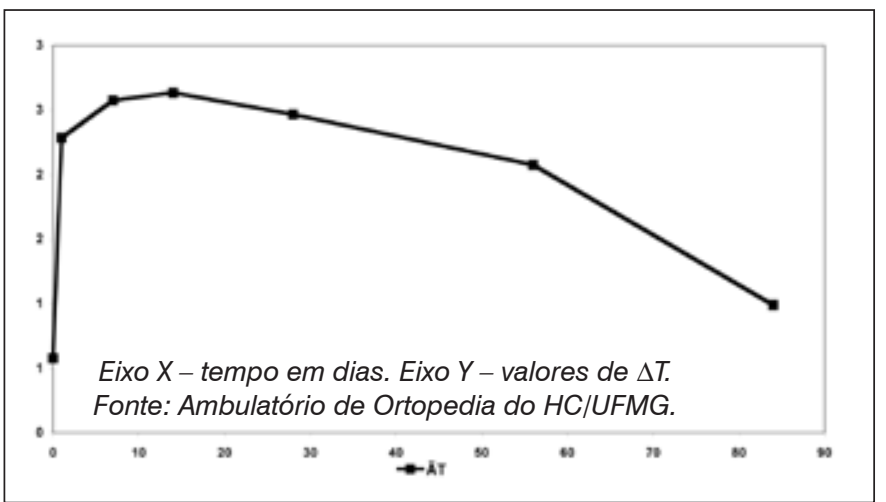

Gráfico 1 - Variação do $\Delta T$ ao longo do tempo.

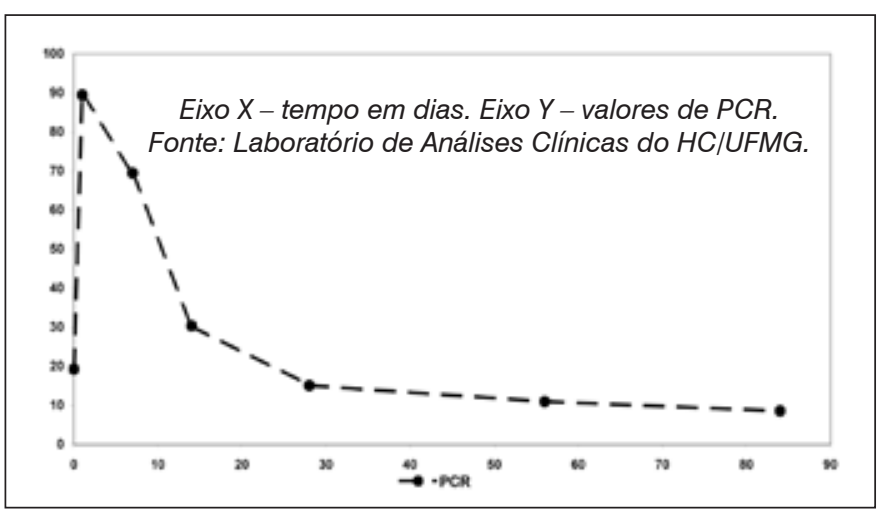

Gráfico 2 - Variação da PCR ao longo do tempo.

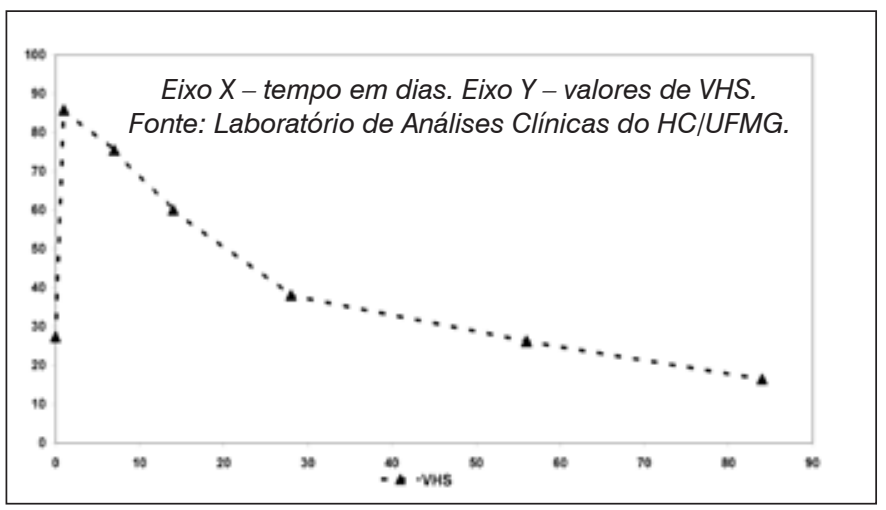

Gráfico 3 - Variação da VHS ao longo do tempo.

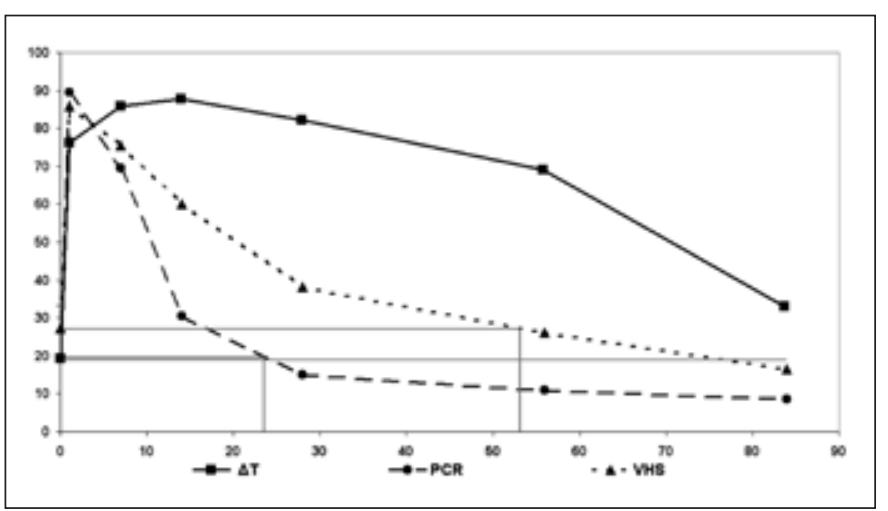

Eixo $X$ - tempo em dias. Eixo $Y$ - valores de $\triangle T$, PCR e VHS. Fonte: Laboratório de Análises Clínicas e Ambulatório de Ortopedia do HC/UFMG.

Gráfico 4 - Variação do $\triangle T$, PCR e VHS ao longo do tempo. tabagismo(12), osteoartrose degenerativa ${ }^{(13)}$, resposta de fase aguda alterada em pacientes idosos ${ }^{(14,15)}$, queimaduras ${ }^{(16)}$, estresse póstraumático(17), altitude ${ }^{(18)}$, desordens emocionais ${ }^{(19,20)}$, ciclo menstrual(20). Nesse estudo, os padrões de variação encontrados nas curvas de PCR e VHS, são compatíveis com as da literatura ${ }^{(1,2,6)}$. A curva da PCR apresentou pico no pós-operatório imediato (primeiro exame póscirúrgico) seguido de redução progressiva dos valores, apresentando normalização antes de decorridos 30 dias, com valores inferiores aos pré-operatórios em 60 dias. Quanto a VHS a literatura é mais controversa, com tendência a retorno para níveis normais entre três e seis meses ${ }^{(5,20)}$, podendo manter-se elevada até um ano após a cirurgia(6). Nesse estudo foi observado pico no pós-operatório imediato (primeiro exame pós cirúrgico), seguido de decréscimo progressivo com tendência a normalização antes de 60 dias, discretamente mais rápido em relação à literatura ${ }^{(5,20)}$, e valores menores do que os pré-operatórios em torno de 90 dias.

O aumento da temperatura cutânea do sítio cirúrgico é sintoma clínico observado normalmente após ATJ isenta de complicações. Até o presente estudo, sua curva de variação normal ainda não fora estabelecida na literatura. Nessa avaliação a curva da $\Delta T$ apresentou pico na aferição pós-operatória imediata mantendo elevação nas duas aferições subseqüentes, sendo que o decréscimo ocorreu a partir de 30 dias e a normalização não foi observada até a décima segunda semana, mantendo-se acima dos 
valores pré-operatórios durante os 90 dias.

A possibilidade de correlacionar o aumento dos valores da PCR e da VHS com a variação da temperatura cutânea poderia estabelecer um padrão clínico, de simples

\begin{tabular}{lccc}
\hline & $\Delta$ T pré-op. & PCR pré-op. & VHS pré-op. \\
\hline$\Delta$ T 12 semanas & $-0,114$ & & \\
PCR 12 semanas & & 0,984 & \\
VHS 12 semanas & & & 0,978 \\
\hline
\end{tabular}

Tabela 3 - Resultados do teste paramétrico de Pearson.
Fonte: HC/UFMG.

artroplastia na redução do processo inflamatório (associado a osteoartrose pré-operatória).

\section{CONCLUSÃO}

No pós-operatório de ATJ primáaplicação e economicamente viável para monitorização pós-operatória, funcionando como parâmetro da resposta inflamatória. Infelizmente tal não foi possível, pois não houve correlação estatística, contudo estabeleceu-se aqui o padrão normal que poderá ser utilizado como referência para casos em que se suspeite de infecção pós-operatória, seja superficial ou profunda. Concordando com achados de Lara et al.(21) foi confirmada a redução significativa dos valores da PCR e da VHS pré-operatórias em relação aos valores obtidos aos 90 dias, ressaltando a importância da ria, isenta de complicações, não se observou correlação entre o comportamento da VHS, da PCR e da diferença entre a temperatura cutânea entre os dois joelhos. A PCR e a VHS retornaram a valores inferiores aos pré-operatórios após 30 e 80 dias respectivamente. A temperatura cutânea não tinha retornado aos seus níveis prévios mesmo após 12 semanas de pós-operatório.

A elevação desses parâmetros dever ser considerada normal no pós operatório das Artroplastias Totais de Joelho, mesmo na ausência de complicações.

\section{REFERÊNCIAS BIBLIOGRÁFICAS}

1. Crockarell JR, Guyton JL. Artroplasty of ankle and knee. In: Campbell's Operative Orthopaedics. 10th ed. Philadelphia: Mosby; 2003. p. 243-314.

2. Tsukayama DT, Gustilo R. Infected total knee artroplasty. In: Knee surgery. 2nd ed. Baltimore: Williams \& Wilkins; 1994. p.1563-72.

3. Nerlich ML, Tscherne H. Biologia das lesões dos tecidos moles. In: Traumatismos do sistema musculoesquelético. 2a. ed.Tradução de Nelson Gomes de Oliveira.São Paulo. São Paulo: Manole; 2003; p.79-95.

4. Kim S, Losina E, Solomon DH, Wright J, Katz JN. Effectiveness of clinical pathways for total knee and total hip arthroplasty: literature review. J Arthroplasty. 2003; 18:69-74

5. Forster IW, Crawfor R. Sedimentation rate in infected and uninfected total hip arthroplasty. Clin Orthop 1982; 168:48-52.

6. Bilgen O, Atici T, Durak K, Karaeminogullari O, Bilgen MS. C-reactive protein values and erythrocyte sedimentation rates after total hip and total knee arthroplasty. J Int Med Res. 2001; 29:7-12.

7. Rosas MH, Leclercq S, Pègoix M, Darlas $\mathrm{Y}$, Aubriot JH, Rousselot $\mathrm{P}$ et al. Contribuition of laboratory tests, scintigraphy, and histology to diagnosis of lower limb joint repleacement infection. Contribution of laboratory tests, scintigraphy, and histology to the diagnosis of lower limb joint replacement infection. Rev Rhum Engl . 1998; 65:477-82.

8. Martin SD, Scott RD, Thornhill TS. Current concepts of total knee arthroplasty. J Orthop Sports Phys Ther. 1998; 28:252-61.

9. Spector TD, Hart DJ, Nandra D, Doyle DV, Mackillop N, Gallimore JR et al. Low-level increase in serum C-reative protein are present in early osteoarthritis of the knee and predict progressive disease. Arthritis Rheum. 1997; 40:723-7.

10. White J, Kelly M, Dunsmuir R. C-reactive protein level after total hip and total knee replacement. J Bone Joint Surg Br. 1998; 80:909-11.

11. Visser M, Bouter LM, McQuillan GM, Wener MH, Harris TB. Elevated C-reactive protein levels in overweight and obese adults. JAMA. 1999; 282:2131-5

12. Crook MA, Scott DA, Stapleton JA, Palmer RM, Wilson RF, Sutherland G. Circulating concentrations of $\mathrm{C}$-reactive protein and total sialic acid in tobacco smokers remain unchanged following one year of validated smoking cessation. Eur J Clin Invest. 2000; 30:861-5.

13. Krabbe KS, Bruunsgaard H, Hansen CM, Moller K, Fonsmark L, Qvist J et al. Ageing is associated with a prolonged fever response in human endotoxemia. Clin Diagn Lab Immunol. 2001; 8:333-8.

14. Bouguiguinat A, Ferard G, Jenny JY, Gaudias J. Incomplete absent acute phase response in some postoperative pacients. Clin Chim Acta. 1997; 264:27-35.

15. Mooser V, Berger MM, Tappy L, Cayeux C, Marcovina SM, Darioli R et al. Major reduction in plasma levels during sepsis and burns. Arterioscler Thromb Vasc Biol. 2000; 20:1137-42.

16. Muller RJ, Sutherland AG, Hutchisom JD, Alexander DA. C-reactive protein and interleukin-6 receptor in post-tramatic stress disorder: a pilot study. Cytokines. 2001; 13:253-5.

17. Hartmann G, Tschop M, Fischer R, Bidlingmaier C, Riepl R, Tschop K, et al. .High altitude increases circulating interleukin-1, interleukin-6 receptor antagonist and C-reactive protein. Cytokines. 2000; 12:246-52.

18. Berk M, Wadee AA, Kuschke RH, O'Neill-Kerr A. Acute phaseproteins in major depression. J. Psychosom Res. 1997; 43:529-34.

19. Horing M, Goodman DB, Kamoun M, Amsterdan JD. Positive and negative acute phase proteins in affective subtypes. J Affect Dis. 1998; 49:9-18.

20. Jilma B, Dirnberger E, Loscher I, Rumplmayr A, Hildebrandt J, Eichler HG et al. Menstrual cycle associated changes in blood levels of interlrukin-6, and C-reactive protein. J Lab Clin Med. 130:69-75.

21. Lara CN, Guedes EC, Vassalo CC, Carvalho Jr. LH. Avaliação da velocidade de hemossedimentação e da proteína C-reativa em pacientes submetidos à artroplastia total do quadril. Rev Bras Ortop. 2005; 40:175-81. 